\title{
CARACTERIZAÇÃO DAS FIGURAS ANTROPOMÓRFICAS DA TRADIÇÃO AGRESTE EM PERNAMBUCO
}

\author{
Alexandre Farias Filho* \\ Daniela Cisneiros** \\ Marília Perazzo***
}

RESUMO: Esta pesquisa teve como objetivo principal caracterizar as figuras antropomórficas de grandes dimensões da Tradição Agreste em Pernambuco. Estes grafismos são considerados emblemáticos de Tradição Agreste, principal classe de grafismo rupestre encontrada em Pernambuco. Na busca por uma recorrência gráfica na representação dos grafismos rupestres em questão, foram aplicados procedimentos metodológicos de ordem operacional e analítica. A aplicação destes procedimentos metodológicos culminou na identificação de quatro tipos gráficos, permitindo ser destacado como representantes dos caracterizadores essenciais da Tradição Agreste o perfil gráfico do tipo 2, compostos por antropomorfos com traços não simétricos e grossos, com membros em posturas forçadas e desproporcionais.

Palavras-chaves: Grafismo Rupestre. Tradição Agreste. Antropomorfo. Pernambuco.

ABSTRACT: This research was to primary objective characterize the big anthropomorphic figures of the Agreste Tradition in Pernambuco. These graphics are considered emblematic of Agreste Tradition, the main class of rock art found in Pernambuco. In the search for a graphical recurrence in the representation of the rock drawings in question, methodological procedures of operational and analytical order were applied. The application of these methodological procedures culminated in the identification of four graphic types, allowing to be highlighted as representatives of the essential characterizers of the Agreste Tradition the type 2 graphic profile, composed of anthropomorphs with non-symmetrical and thick features, with limbs in forced and disproportionate postures.

Keywords: Rock art. Agreste Tradition. Anthropomorphic. Pernambuco. 


\section{Introdução}

A região Nordeste do Brasil reune uma grande quantidade de sítios arqueológicos com grafismos rupestres, concentrados em algumas unidades chamadas de áreas arqueológicas e também distribuídos ao longo de seu território.

Essas pinturas e/ou gravuras realizadas por grupos pré-históricos têm despertado nessa região do Brasil o fascínio e a curiosidade desde os tempos da colonização europeia.

Um dos primeiros registros remonta ao final do século XVI, quando Feliciano Coelho de Carvalho, à época Capitão-Mor da então Capitania da Paraíba, relatou a presença de gravuras no Rio Araçuagipe. Na Capitania da Paraíba, em 1641, Elias Herckman também mencionou a presença de inscrições rupestres (Martin, 2013).

Tristão Alencar Araripe, em 1887, publica "Cidades petrificadas e inscrições lapidares no Brasil", que apesar de está inspirado na lenda das sete cidades, é considerado o primeiro e mais elaborado registro acerca dos registros rupestres no Nordeste do Brasil (Figura 1).

Na primeira metade do século XX, José Azevedo Dantas, também elabora um manuscrito de mais de 200 páginas contendo preciosas reproduções das pinturas e gravuras rupestres na região do Seridó, Rio Grande do Norte (Martin, 2013) (Figura 2).

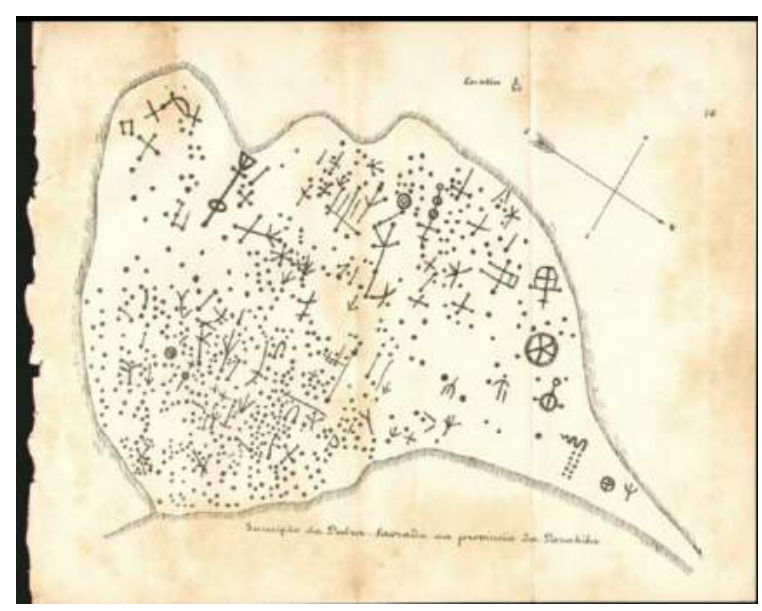

Figura 1: Desenho de Tristão de Araripe (1887) dos grafismos rupestres do sítio Pedra Lavrada - PB. Fonte:https://archive.org/details/Cidades

PetrificadasEInscripcoesLapidaresNoBrazil/page/n119

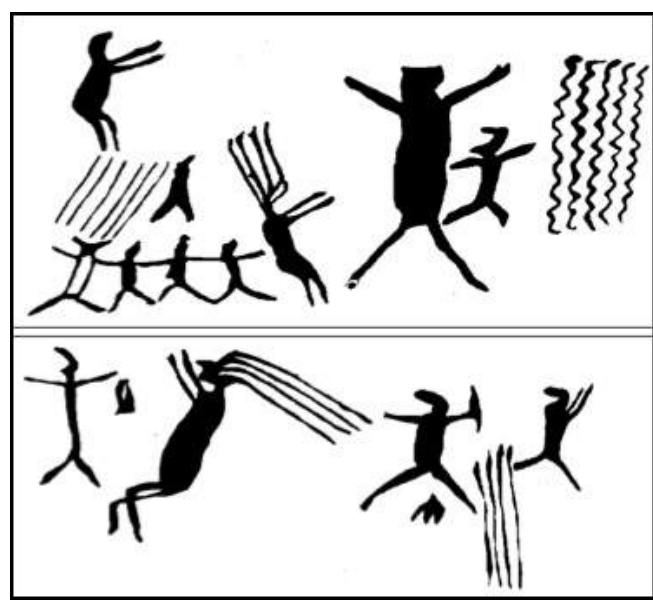

Figura 2: Desenho de J. de Azevedo Dantas (1927) dos sítios da Região do Seridó (PB e RN). Fonte: Dantas, 1994.

Apenas na década de 1970, tem início as primeiras pesquisas arqueológicas voltadas para o estudo dos grafismos rupestres no Nordeste, com os trabalhos de Valentin Calderon pelo 
Pronapa (Programa Nacional de Pesquisas Arqueológicas) na Bahia, e de Niède Guidon com Missão franco-brasileira no sudeste do Piauí.

Inicialmente, as pesquisas ficaram limitadas à descrição dos grafismos, devido à ausência de um contexto arqueológico que pudesse ser utilizado como referência (Pessis, 1992). A técnica utilizada na confecção dos grafismos foi o primeiro critério utilizado, o que segregou os grafismos em dois grupos distintos: os pintados e os gravados. O segundo critério levou em conta a possibilidade de reconhecimento dos grafismos, o que segregou novamente os grafismos em dois grupos distintos: os grafismos reconhecíveis, que permitiam o reconhecimento de elementos do mundo sensível, e os grafismos não reconhecíveis, que não permitiam o reconhecimento dos sinais gráficos representados. Quando se separou os grafismos pintados e reconhecíveis foi possível perceber, novamente, a existência de grupos distintos: grafismos que continham representações de figuras antropomorfas realizando ações da vida cotidiana e cerimonial e grafismos que continham representações de figuras antropomorfas e zoomorfas estáticas, ou seja, sem realizar ações (Cisneiros, 2008).

Coube a Calderon (1970) realizar o primeiro ordenamento para os grafismos rupestres, baseado na apresentação gráfica desses. Para tanto, utilizou o termo "tradição", com o objetivo de distinguir grupos humanos, regiões e técnicas pictóricas. O termo, já era comum nos estudos etnográficos e na classificação das indústrias líticas e cerâmicas, foi aplicado por Calderon (1970), para os grafismos rupestres como sendo:

o conjunto de características que se repete em diferentes sítios de maneira similar, atribuindo cada uma delas ao complexo cultural de grupos étnicos diferentes, que as transmitiam e difundiam, através do tempo e do espaço (Calderon, 1970: 52)

O termo "tradição" passou a ser utilizado pela maioria dos pesquisadores que se interessaram pelo estudo dos grafismos rupestres, sempre com o papel de classificar e ordenar as pinturas e gravuras que iam sendo descobertas, a partir de parâmetros caracterizadores. Para Pessis (1992):

o que se procura estabelecendo tradições é a integração de obras gráficas pertencentes a um mesmo grupo cultural, independentemente de unidade cronológica, e identificar as características dos registros próprias do meio cultural ao qual os autores pertenciam (Pessis, 1992:45). 
O primeiro ordenamento dos grafismos rupestres do Nordeste brasileiro apontou para a existência de quatro tradições: a Tradição Nordeste, a Tradição Agreste, a Tradição Geométrica e a Tradição Itacoatiara.

A Tradição Nordeste foi definida na Área Arqueológica da Serra da Capivara, Piauí, sendo caracterizada por sua técnica aprimorada e variedade extensa de representações, que inclui figuras antropomorfas, zoomorfas, fitomorfas, objetos e grafismos puros, geralmente formando cenas reconhecíveis (Figura 3).

Para Martin (2013):

A Tradição Nordeste é facilmente identificável pela variedade dos temas representados, e a riqueza de enfeites e atributos que acompanham a figura humana, indicadores, seguramente, de diversas hierarquias e diferentes tribos. As figuras humanas são de pequeno tamanho, entre 5 $15 \mathrm{~cm}$, sempre em movimento, às vezes possuídas de grande agitação, com o rosto de perfil e como se gritassem. A luta, a caça, a dança e o sexo são habilmente representados com grande riqueza de interpretações, utilizando-se uma técnica de traço leve e seguro (Martin, 2013: 246)

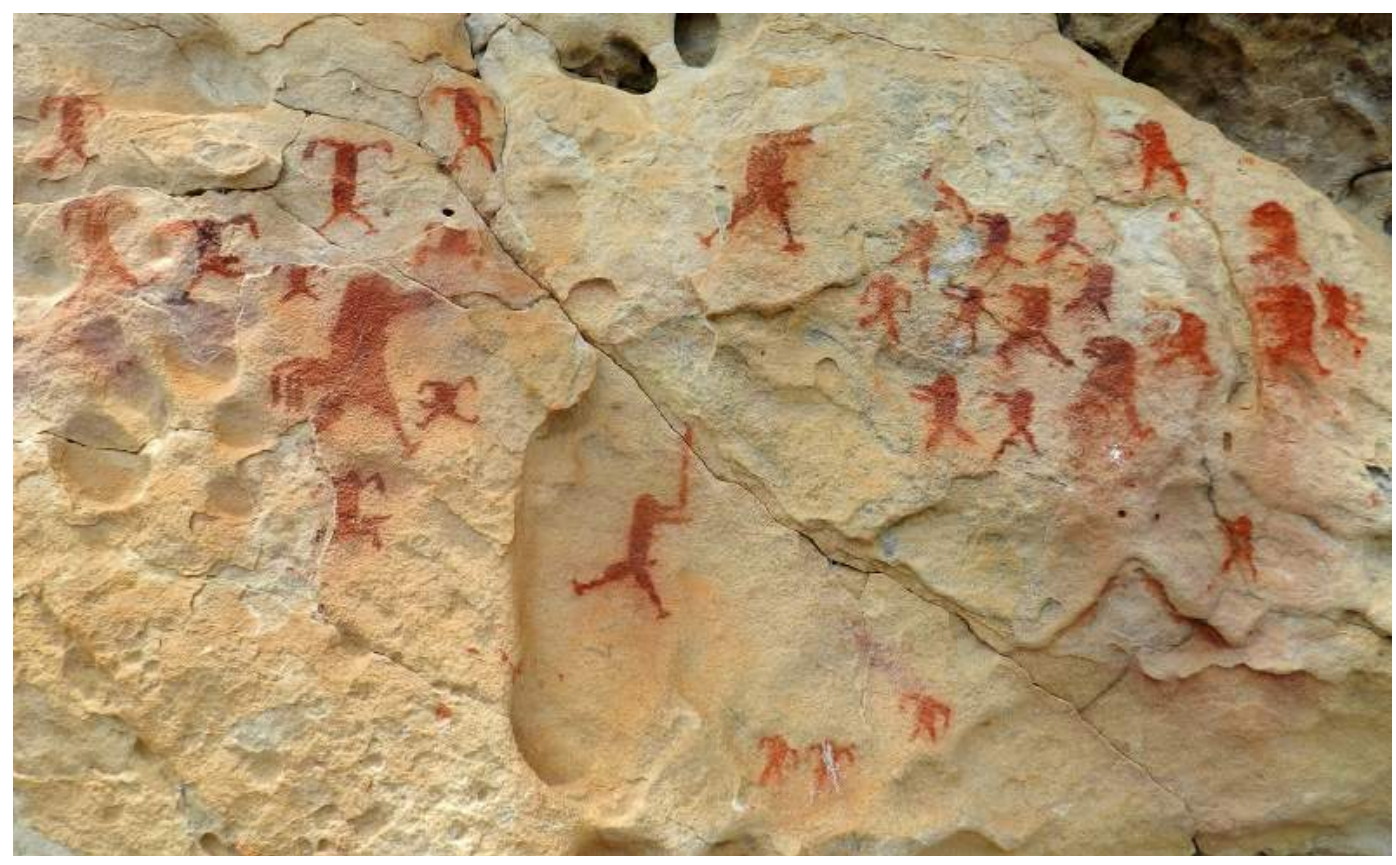

Figura 3: Pintura rupestre caracterizada como pertencente a Tradição Nordeste. Sítio Homem sem Cabeça, Buíque - PE. Fonte: Base de Dados Imagética Facepe-UFPE.

A Tradição Geométrica, classificação pouco estudada, inclui os grafismos puros representados de maneira que remetem às figuras geométricas conhecidas atualmente. Essa tradição não teve seus parâmetros aprofundados para o Nordeste, sendo mais trabalhada para gravuras no 
sudeste do país. Atualmente, em relação as novas referências sobre o assunto, não faz parte mais das classificações de pinturas rupestres para o Nordeste (Figura 4).

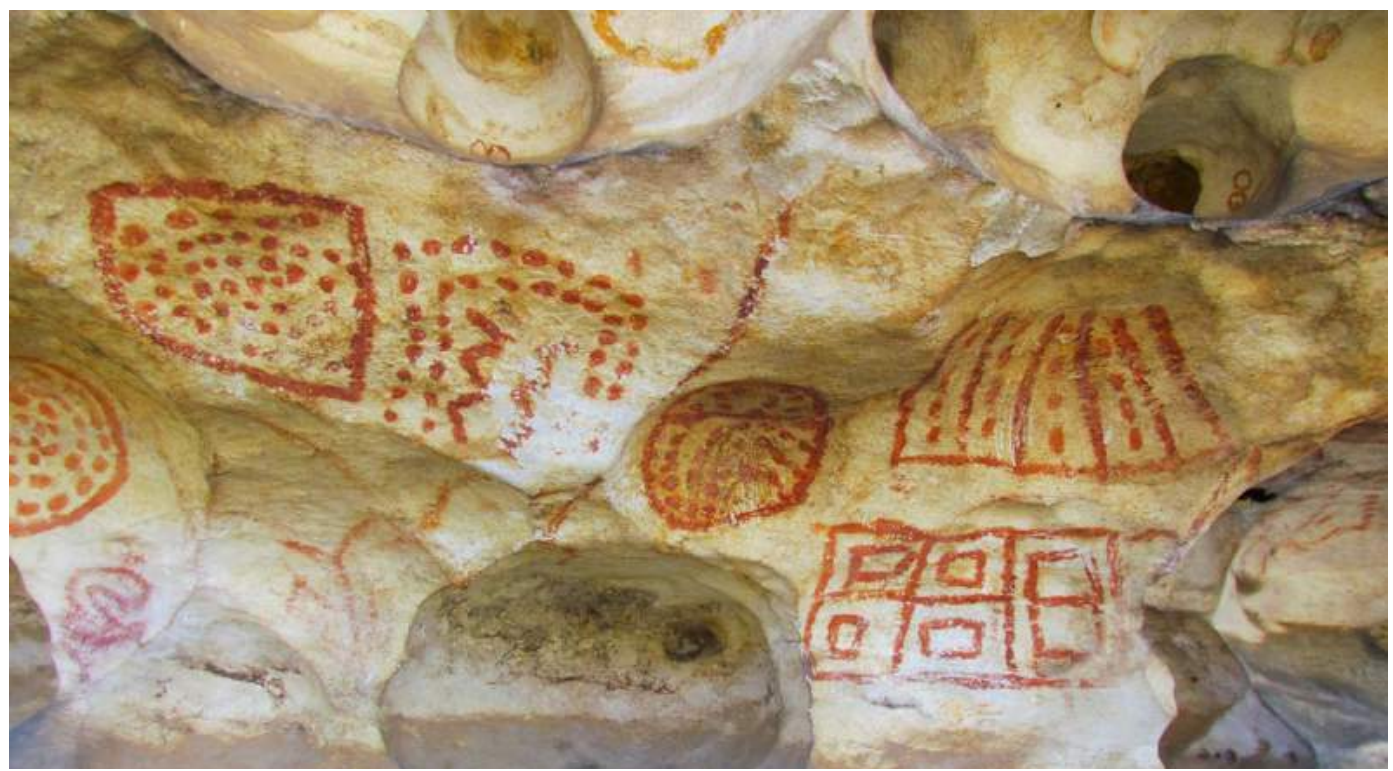

Figura 4: Painel rupestre classificado como tradição geométrica. Sítio Lajedo da Soledade. Apodi -RN. Fonte: Porpino et al (2007)

A Tradição Itacoatiara é uma tradição caracterizada essencialmente por gravuras, geralmente encontradas nas margens de rios e cursos d'água em geral. Em sua maioria, composta por representações de figuras não reconhecíveis, mas com algumas raras figuras reconhecíveis como antropomorfos e zoomorfos (lagartos sobretudo) (Figura 5 ).

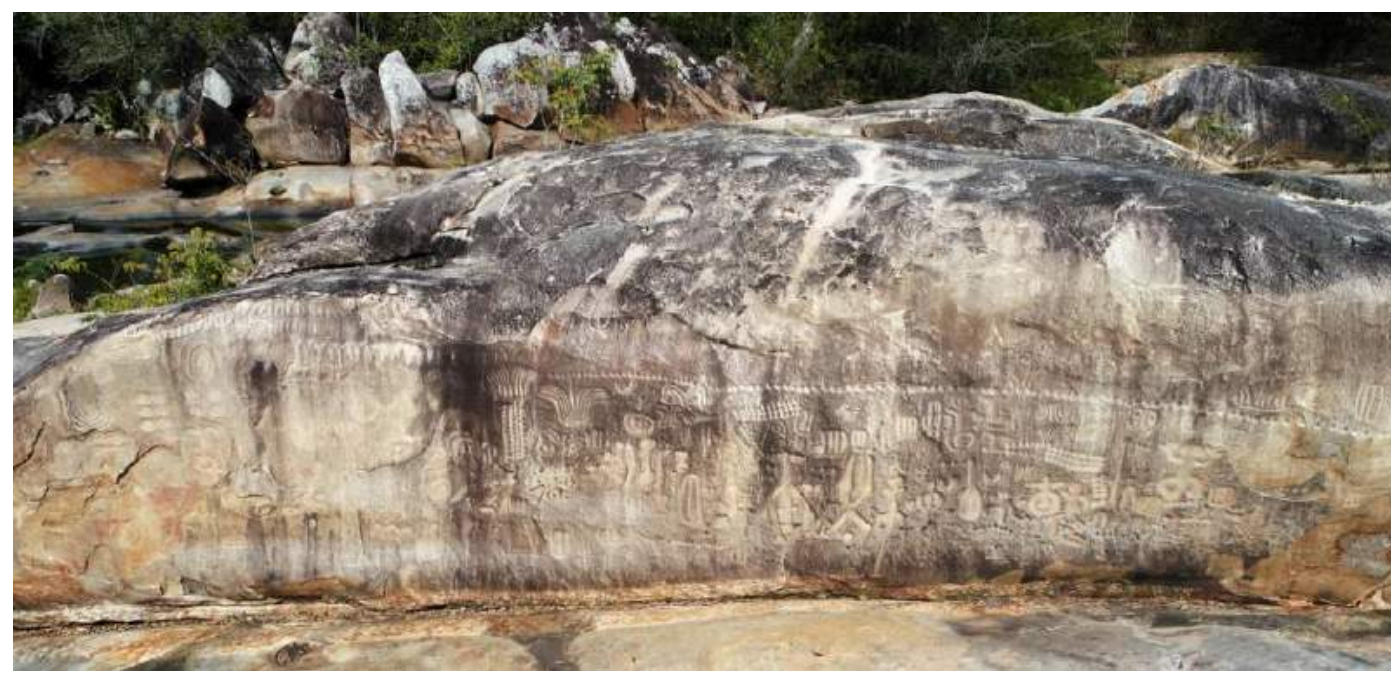

Figura 5: Painel rupestre caracterizado como Tradição Itaquatiara. Sítio Pedra do Ingá, Ingá - PB. Foto: Daniela Cisneiros. 
A Tradição Agreste foi definida, inicialmente, em contraste à Tradição Nordeste, pois, ao contrário desta, não possui grafismos confeccionados com a mesma acuidade técnica e geralmente não formam cenas, sendo representados de forma isolada e estática (Figura 6).

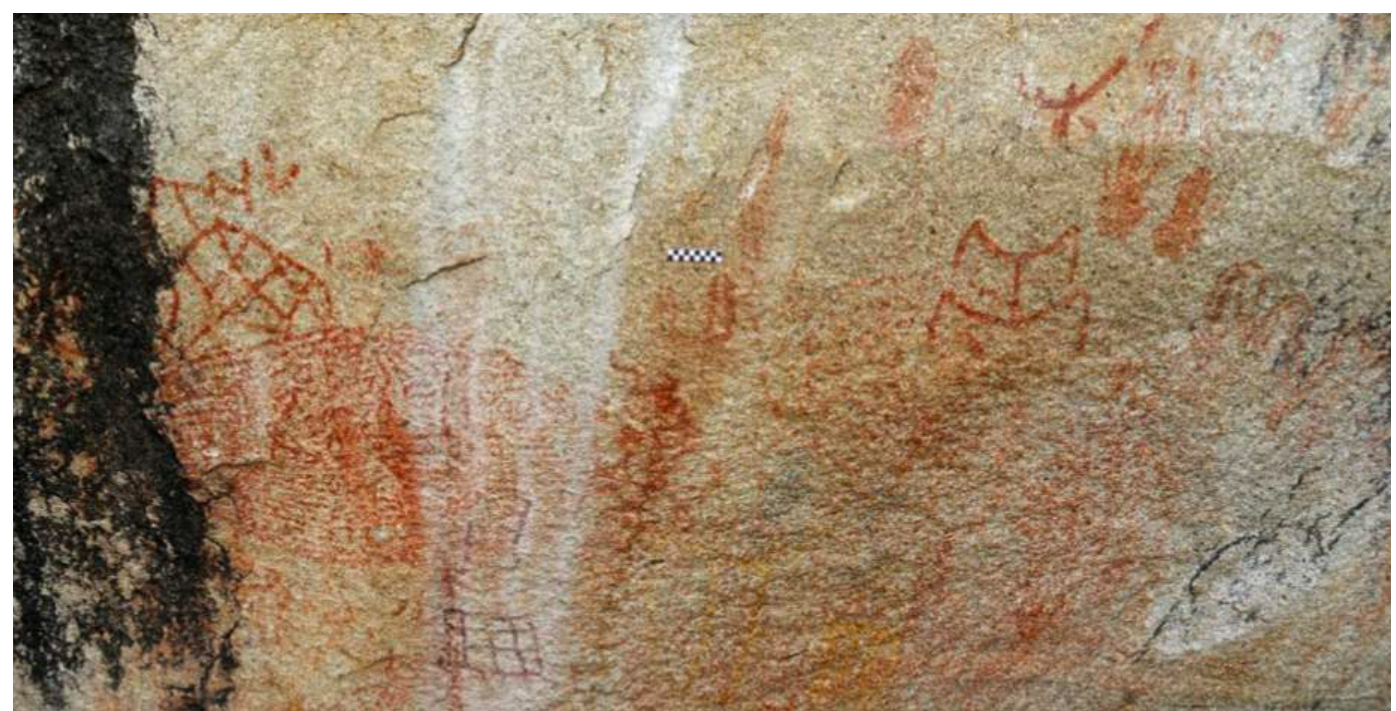

Figura 6: Mancha gráfica caracterizada como pertencente a Tradição Agreste. Sítio Pedra da Buquinha I, Venturosa - PE. Fonte: Amaral (2014)

Posteriormente, foram aplicados às classificações os conceitos de sub-tradição e estilo. 0 primeiro se fundamenta em critérios relacionados à apresentação gráfica e à distribuição geográfica, já o segundo está relacionado à apresentação técnica e na técnica de manufatura dos grafismos.

Para Pessis (1992):

no estabelecimento da tradição procura-se definir identidades culturais, no plano da sub-tradição posicionam-se geograficamente estas identidades, mas no plano dos estilos, diferenças técnicas ou de apresentação gráfica não têm significação maior se não estão inseridos num contexto arqueológico e portanto posicionados cronológicamente (Pessis, 1992: 53).

Acerca da Tradição Agreste, tema deste trabalho, as pesquisas sistemáticas tiveram início nos 1980, com Alice Aguiar e Gabriela Martin e se estendem até os dias atuais, porém não foram estabelecidas sub-tradições para essa tradição. Na sequência, serão apresentadas as principais perspectivas sobre a referida tradição. 


\section{Tradição Agreste}

A Tradição Agreste, inicialmente denominada de Tradição Castelo, é uma classe inicial de estudo das pinturas rupestres. Estudada de forma mais intensiva no agreste do Estado de Pernambuco, onde foi identificada a maior concentração de pinturas incluídas na definição dessa tradição, possui ocorrências em outros estados da região Nordeste do Brasil, como Ceará, Rio Grande do Norte, Paraíba e Piauí (Aguiar, 1986; Martin, 2013).

Tratada inicialmente como de qualidade técnica e temática inferior à Tradição Nordeste, a Tradição Agreste é constantemente caracterizada por seus grafismos de grande tamanho, que, isolados, não formam cenas. Sua figura emblemática ${ }^{1}$ é a representação de figuras com características antropomórficas de grandes dimensões, às vezes com mais de um metro de altura, geralmente isolado e em posição estática, o que gera uma conotação totêmica ao grafismo.

A Tradição Agreste não recebeu em termos de pesquisas a mesma atenção que a Tradição Nordeste, talvez, exatamente, por não possuir a riqueza cenográfica desta e, assim, não fornecer tantos dados interpretativos para os pesquisadores. O certo é que mesmo deixada em segundo plano, a Tradição Agreste teve estudos verticalizados por alguns pesquisadores (Aguiar, 1986; Martin, 2013; Pessis, 2013; Amaral, 2014; Perazzo et al, 2015).

Pessis (2013) estudou o registro rupestre da Tradição Agreste presente no Parque Nacional da Serra da Capivara-PI, considerando-as intrusões isoladas. Apesar da menor presença de pinturas desta tradição frente às mais corriqueiras da Tradição Nordeste, foram identificadas algumas características recorrentes.

Para Pessis (2013), as figuras da Tradição Agreste, inseridas na Área Arqueológica da Serra da Capivara, possuem dimensões maiores que as figuras classificadas como pertencentes à Tradição Nordeste, sendo mais comuns as representações de figuras com características antropomórficas (Figura 7 e 8).

\footnotetext{
${ }^{1}$ Segundo Cisneiros (2008) Figura emblemática é um elemento gráfico que se repete em uma composição característica de uma tradição rupestre.
} 


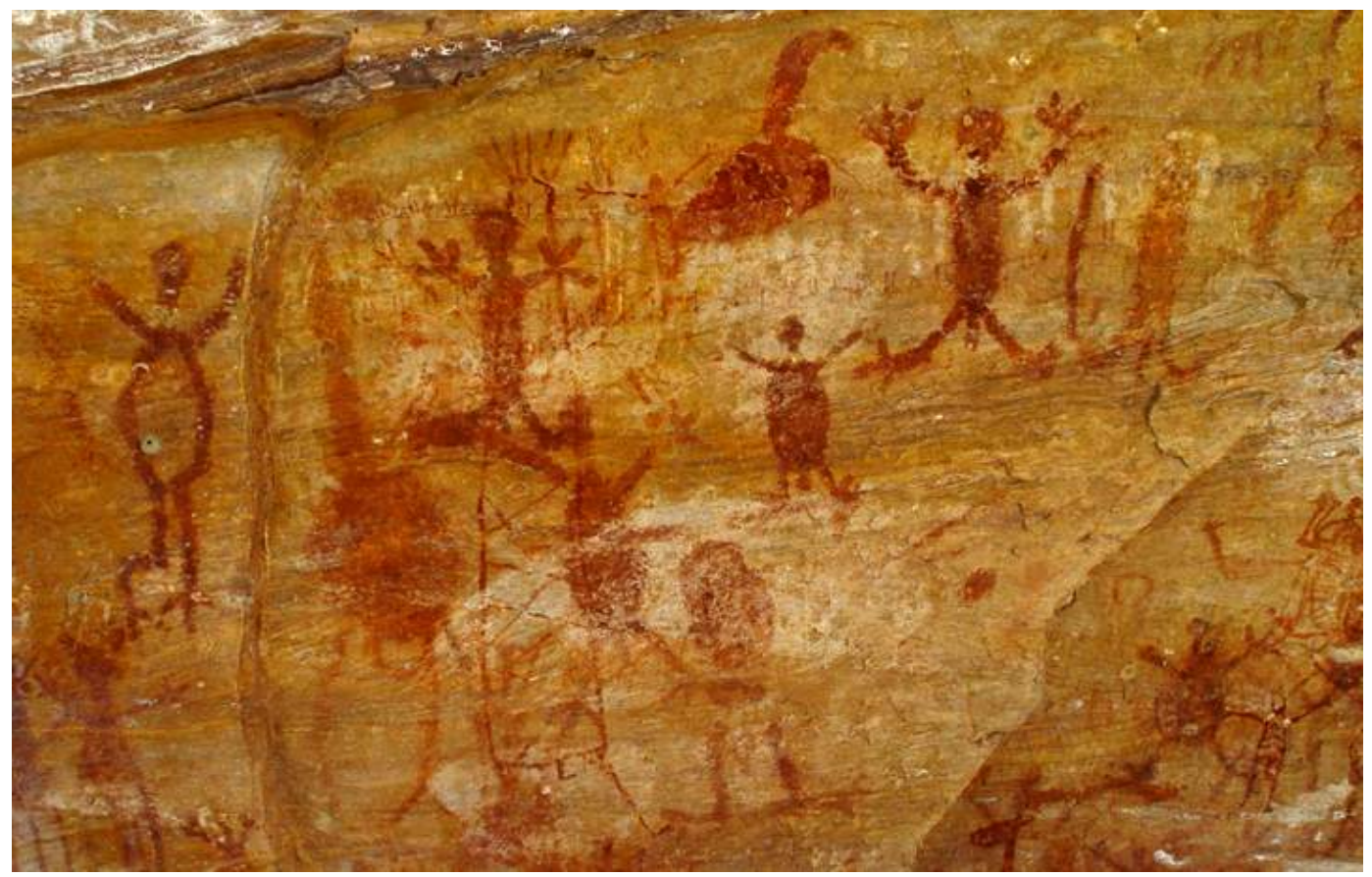

Figura 7: Mancha gráfica característica da Tradição Agreste para a Área da Serra da Capivara. Sítio Toca da Extrema II, Parque Nacional Serra da Capivara - PI. Fonte: Cisneiros (2008)

a) ๆ

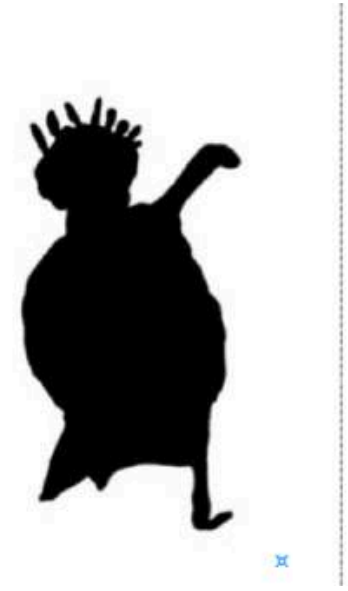

b)ๆ

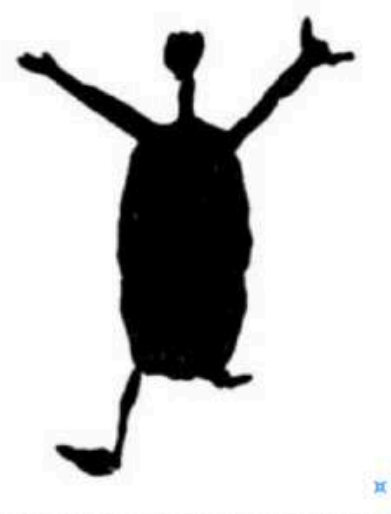

Figura 8: Antropomorfos característicos da Tradição Agreste. A) Sítio Toca da Chapada do Cruz e B) Sítio Toca da Extrema, Serra da Capivara - PI. Fonte: Cisneiros (2008)

As representações de figuras com características zoomórficas são escassas, enquanto as representações de figuras com características fitomórficas são inexistentes, bem como, as representações de objetos. São comuns os grafismos puros. Esses possuem variadas morfologias, coexistindo com as demais representações. Em geral, as pinturas da Tradição Agreste estudadas por Pessis (2013) no Parque Nacional da Serra da Capivara não apresentam cenas narrativas. 
Com o desenvolvimento do "Projeto Agreste", da Universidade Federal de Pernambuco, Aguiar (1986) realizou cuidadosa pesquisa em vinte sítios arqueológicos com ocorrências de registro rupestre da Tradição Agreste, localizados nos municípios pernambucanos de Taquaritinga do Norte, Brejo de Madre de Deus, Venturosa, Pedra, São Bento do Una, Passira, Brejinho, Paranatama e nos municípios paraibanos de São João do Tigre e Cacimba da Areia.

Durante suas pesquisas, Aguiar (1986) identificou representações de figuras com características antropomórficas e zoomórficas, bem como, grafismos puros, que se unem em painéis sem formar cenas complexas. Dessa forma, encontrou poucas cenas que pudessem ser classificadas como de ação. As figuras com características zoomórficas identificadas correspondem à fauna atual, sem ocorrências de representações muito diversificadas. Dentre os animais mais representados estão veados, onças, lagartos e tatus. A impressão de mãos em positivo na parte superior dos painéis foi outra recorrência observada na área de aplicação do Projeto.

Martin (2013) junto com Aguiar identificou e estabeleceu alguns parâmetros caracterizadores para os estudos dos registros rupestres da Tradição Agreste em Pernambuco. Segundo Martin (2013), a Tradição Agreste pode ser individualizada pela coexistência de figuras reconhecíveis e de grafismos puros em um mesmo sítio, pela presença de grafismos de grandes tamanhos e de caráter estático. As figuras com características antropomórficas seriam representadas com aspecto "grotesco", enquanto as figuras com características zoomórficas seriam representadas com poucos detalhes qualificativos, que dificultaria ou impossibilitaria a definição das espécies a que pertenceriam. Já os grafismos puros seriam simples e elaborados.

Posteriormente, Amaral (2014) buscou formular novos parâmetros de análise dos grafismos pertencentes à Tradição Agreste e identificar os seus elementos essenciais ${ }^{1}$ caracterizadores. Para tanto, partiu dos parâmetros estabelecidos preliminarmente por Aguiar (1986) e Martin (2013). Em sua pesquisa trabalhou com um universo de 39 (trinta e nove) sítios arqueológicos localizados nas regiões Agreste e Sertão do Estado de Pernambuco, bem como, da região Agreste do Estado da Paraíba.

A pesquisa culminou com a confirmação de sua hipótese, que defendia que:

os elementos essenciais do que chamamos de Tradição Agreste são figuras formadas por traços irregulares e assimétricos, com desproporcionalidade morfológica e postural, remetendo a figuras 
distorcidas. Assim, as figuras disformes e com ausência de acuidade técnica é o referencial cognitivo desta Tradição (Amaral, 2014:66).

Além disso, constatou outros elementos essenciais ${ }^{2}$ : o reconhecimento cognitivo das figuras; antropomorfos e/ou zoomorfos completamente preenchidos e com irregularidades nas linhas de contorno; traços grossos e espaços gráficos densamente ocupados por grafismos que se apresentam agrupados, mas sem associação entre si, caracterizando-se por figuras individualizadas.

Sua pesquisa também encontrou elementos de variabilidade, ou seja, elementos que detinham características técnicas e de apresentação gráfica diversificadas. São eles: marcas de mãos e grafismos puros confeccionados com diferentes técnicas e formas de apresentação variadas; a presença de figuras ambíguas e poucas representações de elementos secundários, em especial adornos e representações sexuais.

Ao analisar, especificamente, as figuras antropomórficas da Tradição Agreste, Amaral (2014) afirmou que elas apresentam elementos que evocam o caráter humano, pois possuem os constituintes da atividade vital, mas alerta para a falta de harmonia entre as partes que as compõem, que forneceriam a estas uma identidade contra-natura. Afirma, que as posturas e gestualidade representadas no conjunto gráfico da Tradição Agreste remetem, em alguns casos, a posturas forçadas que salientam as características humanas em uma situação de desproporcionalidade. Destaca, ainda, que as figuras antropomórficas se apresentam no corpus gráfico ${ }^{3}$, majoritariamente, em projeção frontal.

Amaral (2014) também estabeleceu medidas que possibilitam classificar, quanto ao tamanho, as representações gráficas da Tradição Agreste em três classes, a saber: pequeno $(10 \mathrm{~cm}$ a 30 $\mathrm{cm}$ ), médio $(31 \mathrm{~cm}$ a $50 \mathrm{~cm}$ ) e grande (maior que $51 \mathrm{~cm}$ ). Esta classificação foi utilizada nesta pesquisa para definir as figuras antropomórficas de grandes dimensões a serem estudadas.

Pessis (2013) atribui uma antiguidade aproximada de 6000 anos B.P. às pinturas da Tradição Agreste. Para tanto, leva em consideração o resultado de escavação arqueológica realizada no sítio Baixão da Perna, que está inserido no Parque Nacional da Serra da Capivara. As pinturas deste sítio apresentavam uma peculiaridade: foram confeccionadas com um cuidado técnico

\footnotetext{
${ }^{2}$ Segundo Cisneiros (2008) os elementos essenciais são os elemento de maior expressão para o reconhecimento cognitivo de uma temática, são os elementos que remetem cognitivamente ao reconhecimento da figura.

${ }^{2}$ Corpus Graficus, é um termo latin utilizado para designar o conjunto gráfico de um painel rupestre (Cisneiros 2008).
} 
maior que o de costume, fazendo Pessis (2013) sugerir a possibilidade de uma transformação estilística da Tradição Agreste.

Segundo Martin (2005) para os sítios caracterizados como tradição Agreste em Pernambuco tem-se datações em torno de $1760 \pm 160$ anos B.P para o sítio Peri-Peri, no município de Venturosa, e para o sítio Pedra do Tubarão com $2030 \pm 50$ anos B.P, "obtidos a partir de fragmentos de ocre, misturados com matéria orgânica, com marcas de raspagem e pequenos recipientes em que se teria preparado o pigmento" (Martin, 2005: 28).

Para o Sítio Alcobaça, no município de Buíque, foram obtidas também datações entre $1785 \pm$ 49 anos B.P e $1766 \pm 24$ anos B.P. associadas a óxido de ferro com marcas de uso. De certo nenhuma dessas datações é direta para as pinturas rupestres da Tradição Agreste em Pernambuco, porém, insere os sítios e a ocupação da área em uma baliza temporal holocênica.

\section{Método}

A região do Agreste pernambucano foi a escolhida para ser o cenário ambiental desta pesquisa, por apresentar alta concentração de sítios arqueológicos contendo grafismos rupestres da Tradição Agreste. Para selecionar a amostra a ser estudada escolheu-se as figuras antropomórficas de grandes dimensões, seguindo o tamanho modal defendido por Amaral (2014), que é a medida igual ou superior a $51 \mathrm{~cm}$. Essas figuras são emblemáticas da Tradição Agreste e se apresentam como um dos elementos caracterizadores dessa Tradição.

$\mathrm{Na}$ área delimitada, foram identificados 184 sítios arqueológicos contendo grafismos rupestres, sendo 67 na microrregião Vale do Ipanema, 82 na microrregião Vale do Ipojuca, 8 na microrregião Médio Capibaribe, 13 na microrregião Alto Capibaribe, 5 na microrregião Brejo pernambucano e 9 na microrregião Garanhuns (Pessis et al, 2017). Nestes, foram identificadas 14 representações de figuras antropomórficas de grandes dimensões em 10 sítios arqueológicos (Figura 9).

Os municípios em que se encontram os sítios arqueológicos selecionados são: Belo Jardim, Brejo da Madre de Deus, Caruaru, Lagoa dos Gatos, Pedra e Venturosa.

\footnotetext{
${ }^{4}$ A pesquisa imagética teve como base a documentação produzida pelo Projeto Caracterização dos Sítios Arqueológicos com Registros Rupestres do Estado de Pernambuco, coordenado pela Dra. Anne-Marie Pessis e financiado pela Facepe (Fundação de Amparo à Ciência e à Tecnologia do Estado de Pernambuco), este banco de dados, encontra-se disponível no Laboratório de Registro Rupestre do Departamento de Arqueologia da Universidade Federal de Pernambuco.
} 


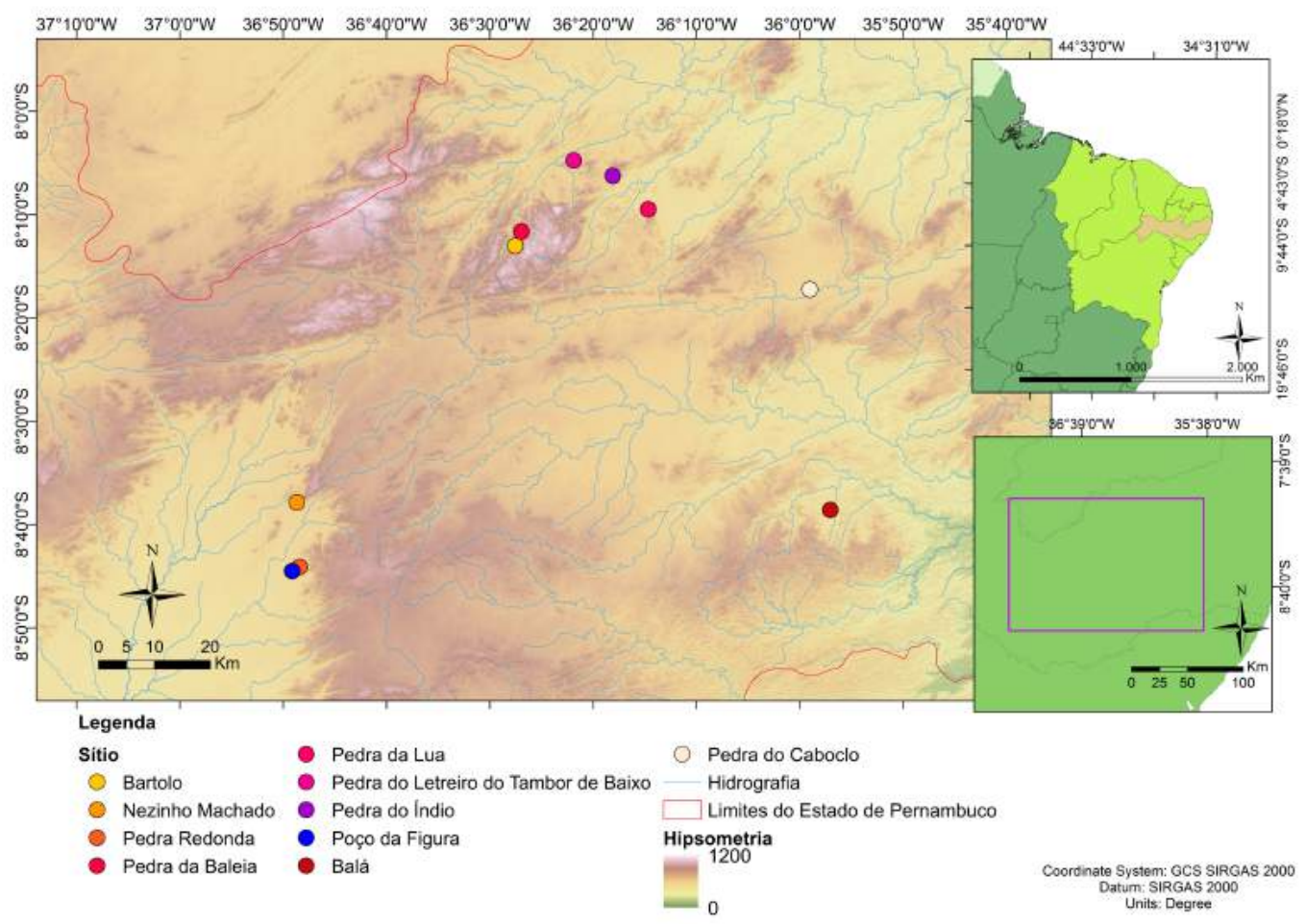

Figura 9: Mapa hipsométrico com a distribuição dos sítios pesquisados. Fonte: Farias Filho (2018).

O perfil gráfico, foi utilizado nessa pesquisa como um instrumento metodológico o qual permitirá sistematizar os dados, um instrumento de comparação entre as estruturas cenográficas onde são analisados os elementos caracterizadores em um nível quantitativo e qualitativo (Cisneiros, 2008).

Cisneiros (2008), define um perfil gráfico como uma estrutura caracterizada por elementos temáticos, cenográficos e técnicos, organizados segundo regras de hierarquia. Aqui no entanto utilizaremos a cenografia como elemento norteador do perfil dos antropomorfos de grande dimensão.

Cada uma das classes componentes do fenômeno gráfico foi trabalhada separadamente e dividida em subclasses a fim de segregar os dados para que cada figura tenha seus próprios caracterizadores e depois estes sejam agrupados e analisados.

As variáveis analíticas da cenografia dos grafismos rupestres estabelecidas para a análise dos Antropomorfos foram: Elementos primários, Elementos secundários, Tamanho, Espessura do traço, Cor, Preenchimento, Associação com outros elementos gráficos, Projeção e Morfologia (Quadro 1). 


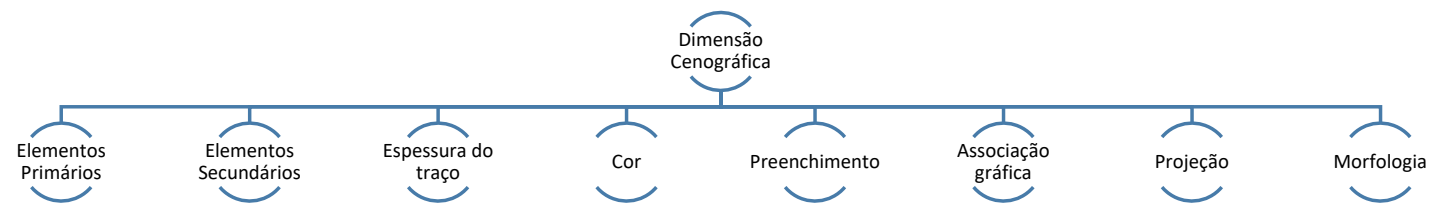

Os elementos primários se referem aos elementos cognitivos de reconhecimento das figuras antropomorfas, que são a presença de cabeça, tronco, membros superiores e membros inferiores.

Os elementos secundários se referem aos elementos que não são imprescindíveis para o reconhecimento do grafismo, mas que the conferem informações adicionais. Podem ser classificados como físicos ou culturais. Os primeiros seriam relativos à sua morfologia física, como pés, mãos e indicativos de sexo (falos ou vulva), por exemplo, enquanto os culturais seriam os adornos ou objetos.

A espessura do traço, se refere à dimensão do traço utilizado na constituição do grafismo, podendo ser atribuído a classificação de fino ou grosso.

A cor se refere a tonalidade apresentada nos grafismos rupestres estudados. Na área desta pesquisa é mais comum a presença de tonalidades em vermelho, porém são registrados grafismos confeccionados em outras tonalidades, como o branco, por exemplo.

O preenchimento, se refere ao possível preenchimento da área interna do grafismo, podendo ser completo, parcial, ausente, simples ou composto. É possível, também, que o grafismo apresente apenas o contorno que o constitui, tornando nula essa variável.

A associação gráfica se refere à possibilidade do grafismo estar relacionado a outro, formando uma cena.

A projeção se refere a de que maneira os grafismos se apresenta no espaço gráfico se foi desenhado de topo, frontal ou lateral.

A morfologia foi estudada visando perceber a construção gráfica que orientou a forma do grafismo. 


\section{Análise e discussão}

Os 10 (dez) sítios arqueológicos onde foram identificados antropomorfos de grandes dimensões estão localizados em seis municípios distintos: sendo 02 (dois) no município de Belo Jardim, 03 (três) no município de Brejo da Madre de Deus, 01 (um) no município de Caruaru, 01 (um) no município de Lagoa dos Gatos, 02 (dois) no município de Pedra e 01 (um) no município de Venturosa (Quadro 2).

Quadro 2: Nome dos sítios arqueológicos pesquisados

\begin{tabular}{|c|c|}
\hline Sítio Arqueológico & Município \\
\hline Bartolo & Belo Jardim \\
\hline Pedra da Baleia & Belo Jardim \\
\hline Pedra da Lua & Brejo da Madre de Deus \\
\hline Pedra do Letreiro do Tambor de Baixo & Brejo da Madre de Deus \\
\hline Pedra do Índio/Pedra do Caboclo & Brejo da Madre de Deus \\
\hline Pedra do Caboclo & Caruaru \\
\hline Balá & Lagoa dos Gatos \\
\hline Pedra Redonda & Pedra \\
\hline Poço da Figura & Pedra \\
\hline Nezinho Machado & Venturosa \\
\hline
\end{tabular}

Esses sítios apresentam um padrão de um antropomorfo de grandes dimensões por sítio, excetuando os sítios: Balá - que tem duas figuras; o sítio Poço da Figura - que tem duas figuras, embora estas estejam localizadas em painéis distintos do sítio e o sítio Pedra do Caboclo que possui um conjunto hermético com três antropomorfos juntos. No total, foram selecionadas 14 (catorze) figuras antropomórficas para análise.

Esses sítios configuram-se em 7 (sete) matacões, 1 (um) céu aberto e 2 (dois) abrigos sob rocha. Esse tipo de formação - matacão, é dominante entre os sítios do Agreste Pernambucano, trata-se de pequenos afloramentos rochosos ou blocos rolados, sítios que não permitem permanência prolongada, por não disponibilizar de grandes áreas abrigadas, o que sugere estes como pontos de passagem de grupos humanos e não de permanência. 
A área estudada apresenta sítios tanto em arenito quanto em granito, mas, para a amostra selecionada a composição granítica foi hegemônica.

Em relação a escolha da superfície do suporte, também se observou que as pinturas foram realizadas todas diretamente na superfície rugosa da rocha, sem um tratamento prévio. Os problemas intempéricos que incidem sobre a superfície rochosa muitas vezes condicionam a execução técnica dos grafismos e outras vezes impedem ou interferem na leitura completa do mesmo. Foi observado que o córtex inicial da rocha já tinha sido desplacado quando houve a pintura no sítio Pedra do Nezinho Machado, indicando que a execução gráfica foi realizada sem importar o que era córtex natural e o que já tinha sido desplacado, assim, algumas figuras estão no córtex inicial e outras na área desplacada. Já no sítio no sítio Pedra do Letreiro do Tambor de Baixo, o córtex se desprendeu posteriormente a execução da pintura, impossibilitando a sua visualização completa.

A primeira variável de análise foi a que se trabalhou os elementos primários de reconhecimento. Todos os antropomorfos da amostra pesquisada apresentavam os elementos primários: cabeça, tronco, membros superiores e membros inferiores. No antropomorfo do sítio Pedra do Letreiro do Tambor de Baixo, mesmo parcialmente danificado pelo desplacamento que atinge a superfície do abrigo, é possível o reconhecimento dos elementos primários. O sítio Pedra do Índio também destaca-se por apresentar uma cabeça muito perto do tronco quase unida diretamente ao tronco, mesmo assim, a união dos demais elementos apresentados sugerem cognitivamente se tratar de uma cabeça.

Em relação à variável elementos secundários constatou-se a representação de pés em 10 (dez) antropomorfos, de mãos em 9 (nove) antropomorfos. Esses marcadores não são muito comuns em antropomorfos nas tradições rupestres do Nordeste do Brasil, mas na amostra levantada tem presença dominante pois dos 14 antropomorfos estudados mais de $80 \%$ possuem pé e mãos (Quadro 3).

Em relação aos indicadores sexuais, foi observado na amostra analisada que 5 (cinco) grafismos apresentavam indicadores sexuais, relacionado a representação do falo. Esses grafismos estão distribuídos nos sítios Pedra da Baleia, Balá, Poço da Figura e Nezinho Machado. 
Quadro 3: Exemplos de grafismos com mãos e pés representados.

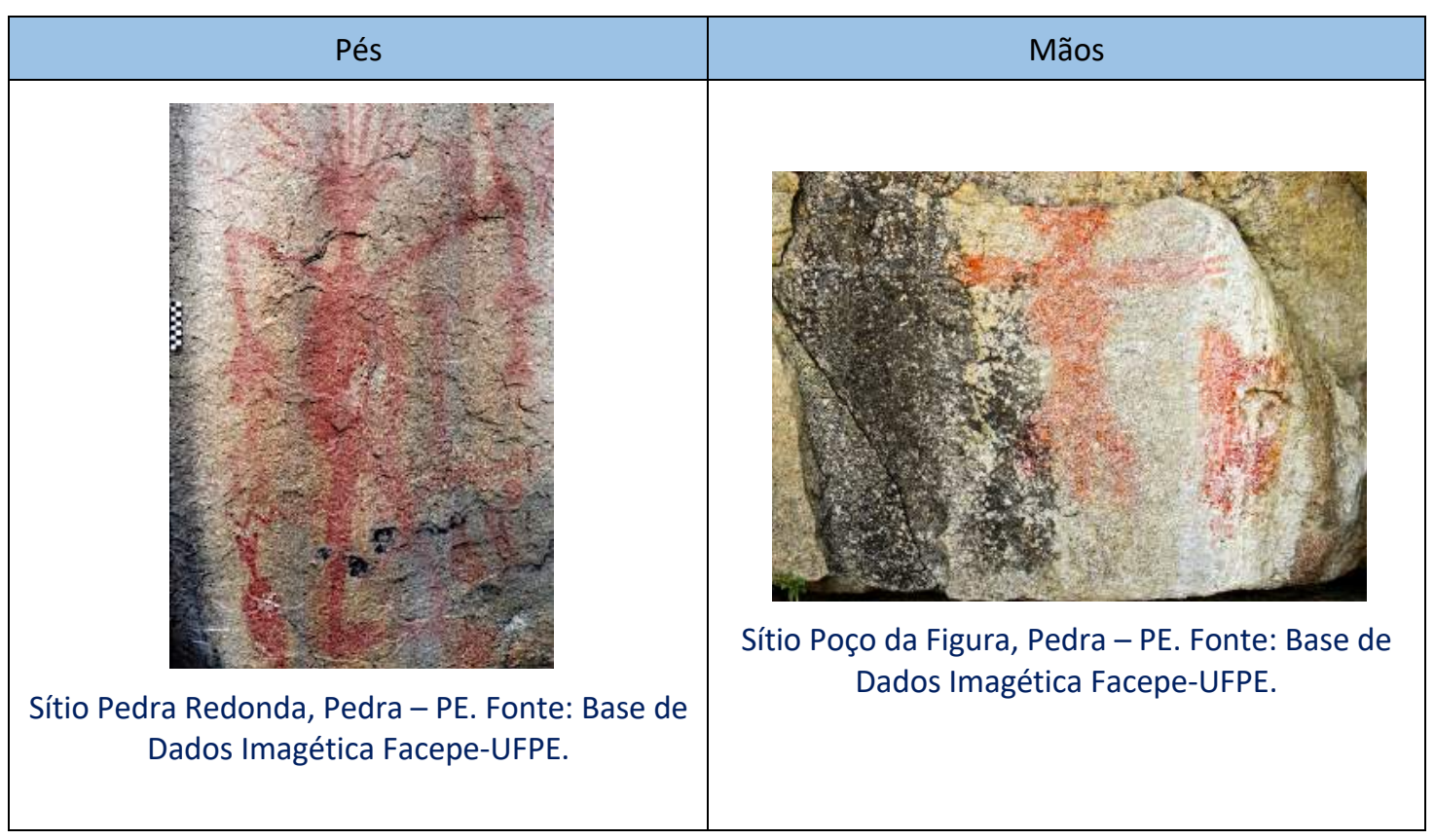

A presença de indicadores sexuais é uma questão bastante discutida nos registros rupestres, por duas razões. A primeira refere-se a dúvida se a presença do falo remeteria realmente a um indicativo de gênero, ou poderia ser um elemento simbólico masculino, mas não necessariamente se trataria de um antropomorfo masculino, já que muitos antropomorfos não possuem esse indicativo. Assim, a representação do falo poderia estar mais ligada a indicadores de outras ordens como poder, linhagens, do que mesmo representativo de sexualidade. O segundo ponto discutido em relação a representação gráfica é que muitas vezes por se tratar de imagens que não são harmônicas o falo ganha um tamanho desproporcional em relação ao grafismo representado, e muitas vezes pode confundir com uma calda, e a depender de outros elementos gráficos a figura pode ganha um status de híbrida onde não se tem elementos suficientes para a distinção entre zoomorfo e antropomorfo. Para as amostras analisadas todas as representações eram itifálicas (Quadro 4).

Em relação aos indicadores culturais, tais como adornos e objetos que acompanham a imagem antropomorfa, foi observada em duas amostras, antropomorfos que carregam em suas cabeças imagens que podem ser associadas a adornos. Esses antropomorfos foram identificados nos sítios Pedra Redonda e Poço da Figura (Quadro 4). 
Quadro 4: Exemplos de grafismos com indicadores sexuais (falo) e indicadores culturais (adornos) representados

\begin{tabular}{|c|c|}
\hline Indicador de sexo - falo & Indicador cultural - adorno \\
\hline$\alpha$ & \\
\hline Sítio Pedra da Baleia, Belo Jardim - PE. Fonte: & Sítio Poço da Figura, Pedra - PE. Fonte: Base de \\
Base de Dados Imagética Facepe-UFPE. & Dados Imagética Facepe-UFPE. \\
\hline
\end{tabular}

Em relação à variável cor, dos 14 (quatorze) grafismos estudados apenas um foi confeccionado na cor branca, o antropomorfo do sítio Pedra da Lua, em Brejo da Madre de Deus, todos os demais antropomorfos foram confeccionados unicamente na cor vermelha.

Essa dominância de pigmentos na cor vermelha é observada para o conjunto de grafismos da região. Estudos em outras regiões como Serra da Capivara, tem associado esse pigmento a hematita, mineral comum na região (Quadro 5).

Quanto ao preenchimento, verificou-se como dominante o preenchimento completo do espaço gráfico, apenas um antropomorfo apresenta-se com preenchimento parcial interno. 0 antropomorfo do sítio Pedra do Índio, em Brejo da Madre de Deus, é a exceção à regra, esse é constituído apenas pelo traço de contorno, chamado contorno aberto, onde a figura não precisa ter seus traços totalmente fechados para a compreensão de seu espaço gráfico (Quadro 6). 


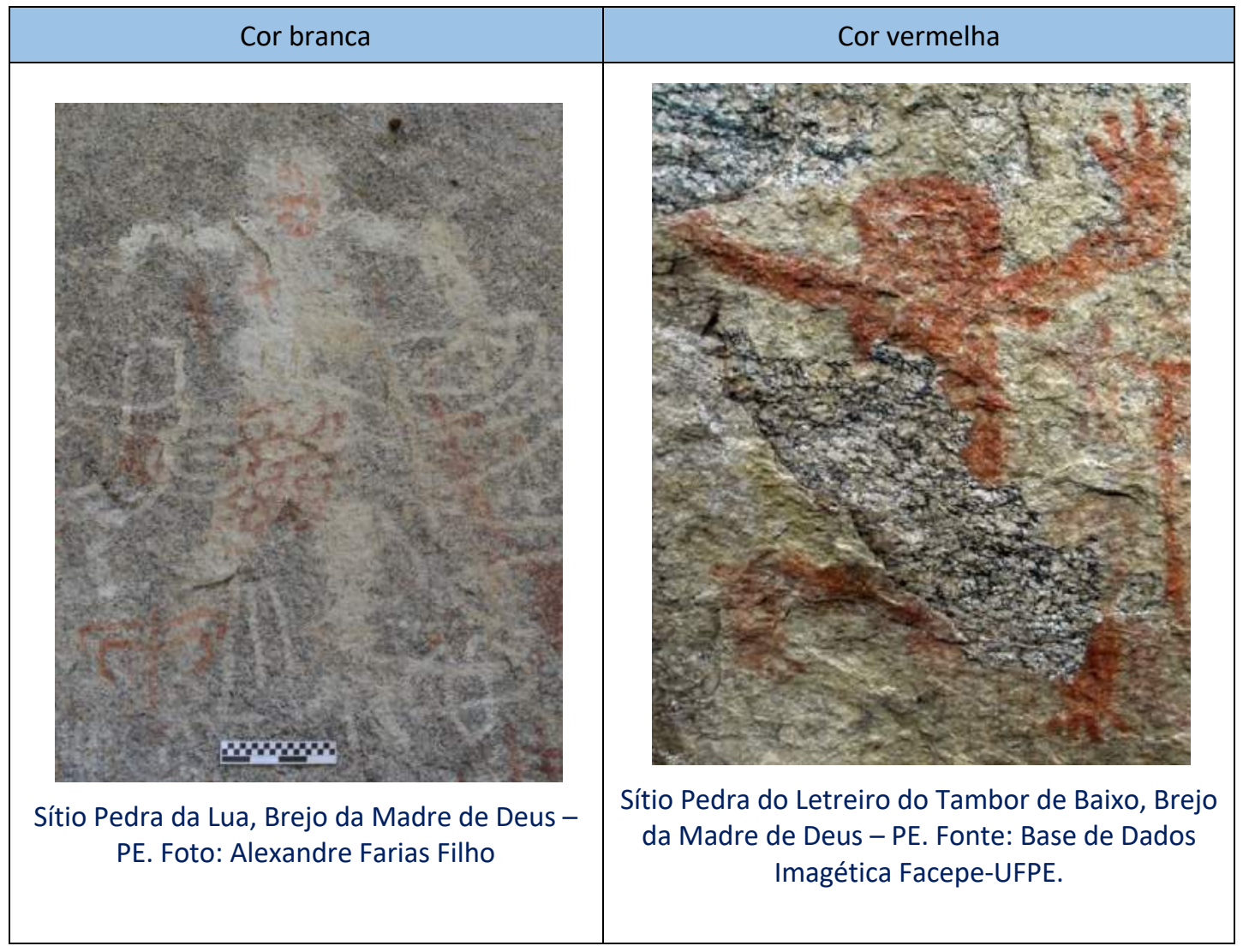

Quadro 6: Tipo de preenchimento

\begin{tabular}{|c|c|}
\hline Preenchimento Completo & Preenchimento parcial \\
\hline & \\
\hline
\end{tabular}


Esse tipo de figura é bastante recessivo para a área. Foi estudada na região da Serra da Capivara por Cisneiros (2008), onde se apresenta como um estilo distinto dos demais apresentados nessa região, tanto como expressão gráfica, quanto disposição espacial.

Quanto a associação gráfica, verificou-se que dentre as amostras estudadas, apenas três formam uma composição. Esses três antropomorfos estão representados juntos no sítio Pedra do Caboclo. Esses grafismos aparecem juntos, sem outra qualquer representação no entorno, se tratando de uma cena hermética (Figura 10).

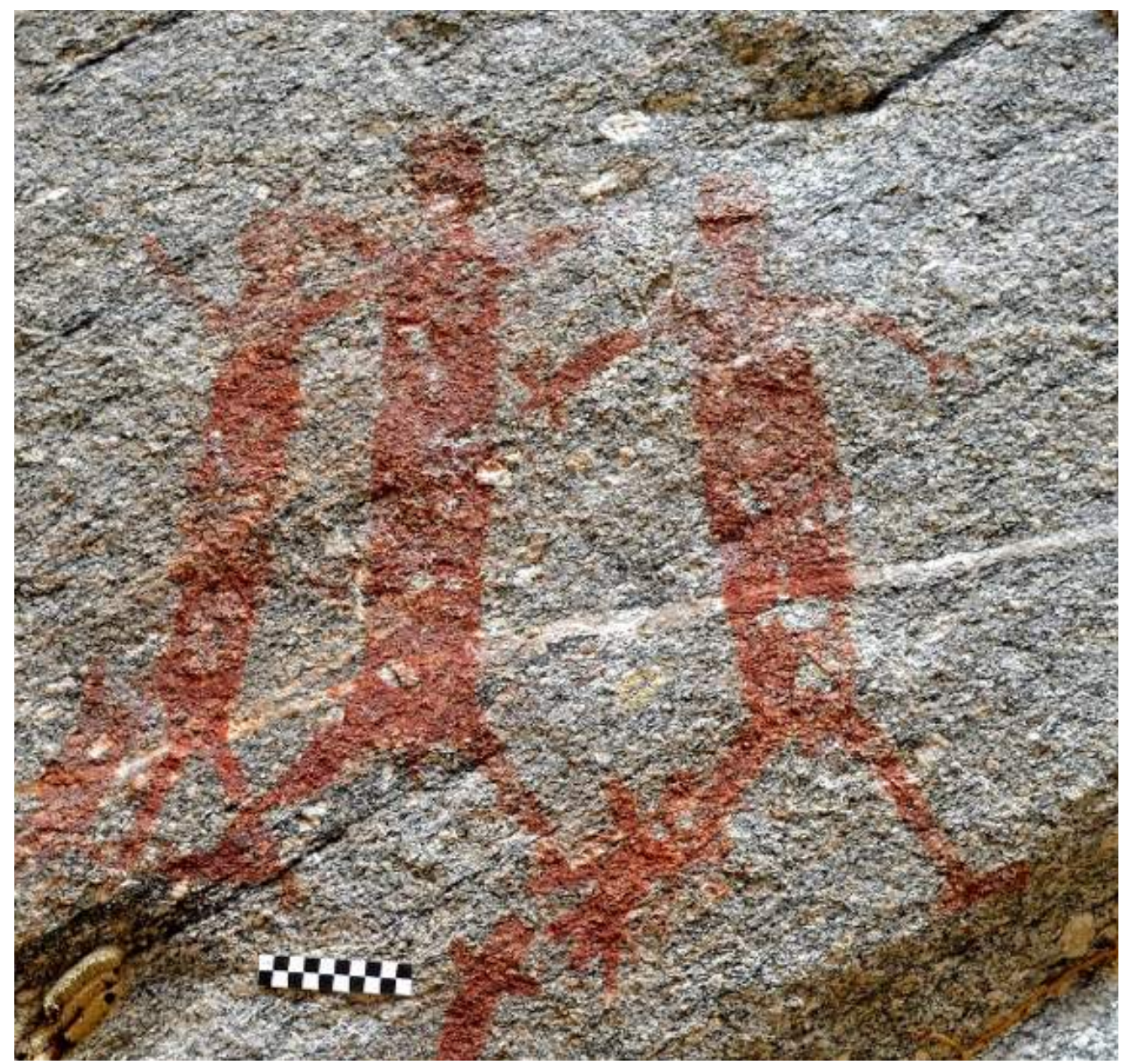

Figura 10: Exemplares únicos de antropomorfos em grandes dimensões em composição. Sítio Pedra do Caboclo, Caruaru - PE. Fonte: Base de Dados Imagética Facepe-UFPE.

Quanto a forma de apresentação, todas as figuras antropomorfas estudadas foram desenhadas de forma frontal. 
Ao observar o traço em que foi desenhado os antropomorfos, pode-se notar dois tipos de traço: um traço mais fino e preciso, com maior simetria ao longo do espaço desenhado e outro traço mais grosso, sem maior acuidade de precisão. Em relação a morfologia dos corpos dos antropomorfos, observou-se figuras lineares - longilíneas e figuras mais retangulares robustas.

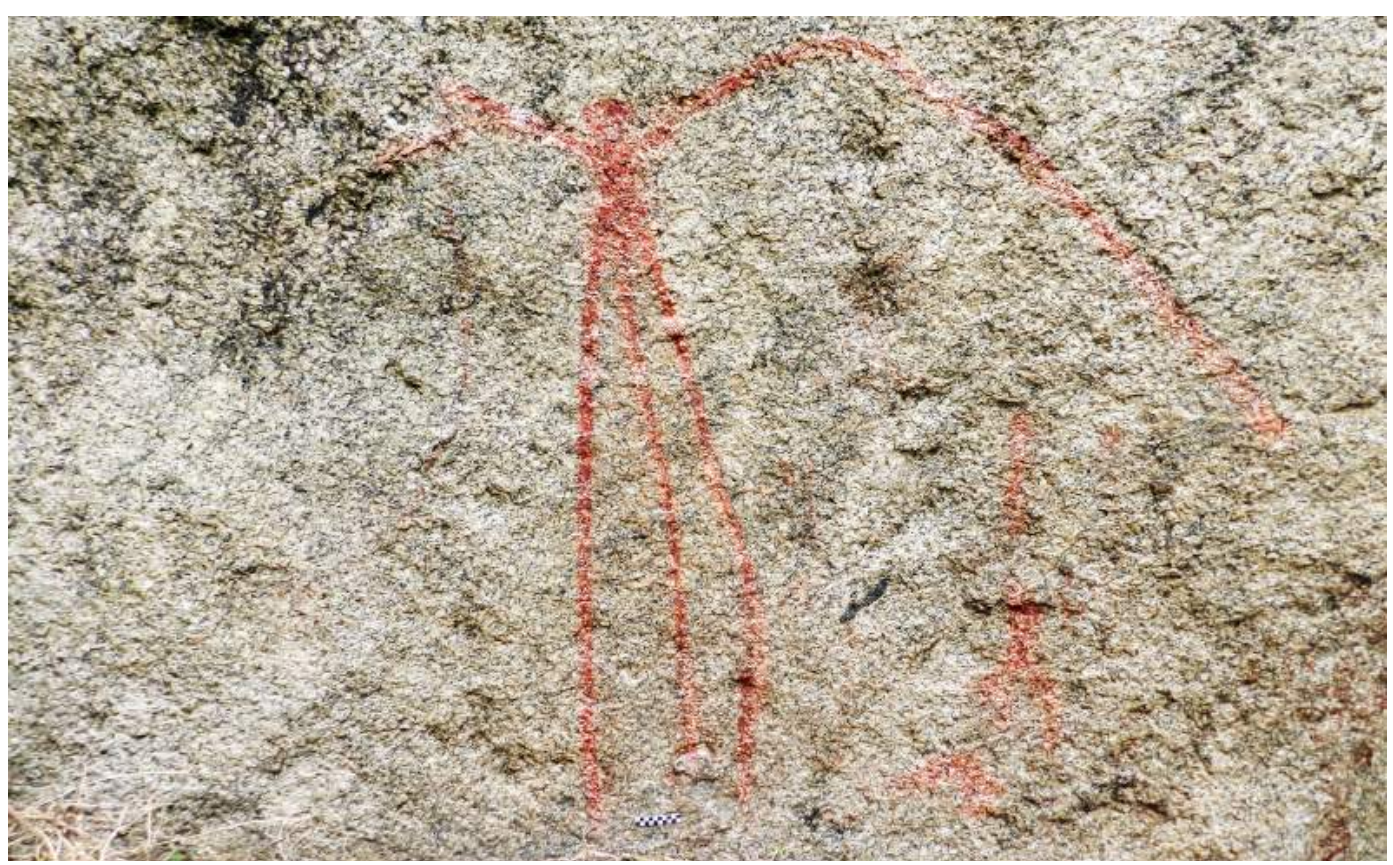

Figura 11: Exemplo de antropomorfos em grandes dimensões com traço fino. Sítio Balá, Lagoa dos Gatos - PE. Fonte: Base de Dados Imagética Facepe-UFPE.

A partir da união entre essas duas variáveis morfologia e tipo de traço, pode ser observado a distinção gráfica de quatro tipos de antropomorfos (Quadro 7).

\section{Considerações Finais}

O trabalho exposto teve por objetivo caracterizar os antropomorfos de grandes dimensões, privilegiando sua apresentação gráfica. Estes grafismos representam um conjunto particular no universo da Tradição Agreste, assim foram utilizados para analisa-los os parâmetros destacados para essa Tradição. 
Quadro 7: Apresentação dos tipos quanto a morfologia

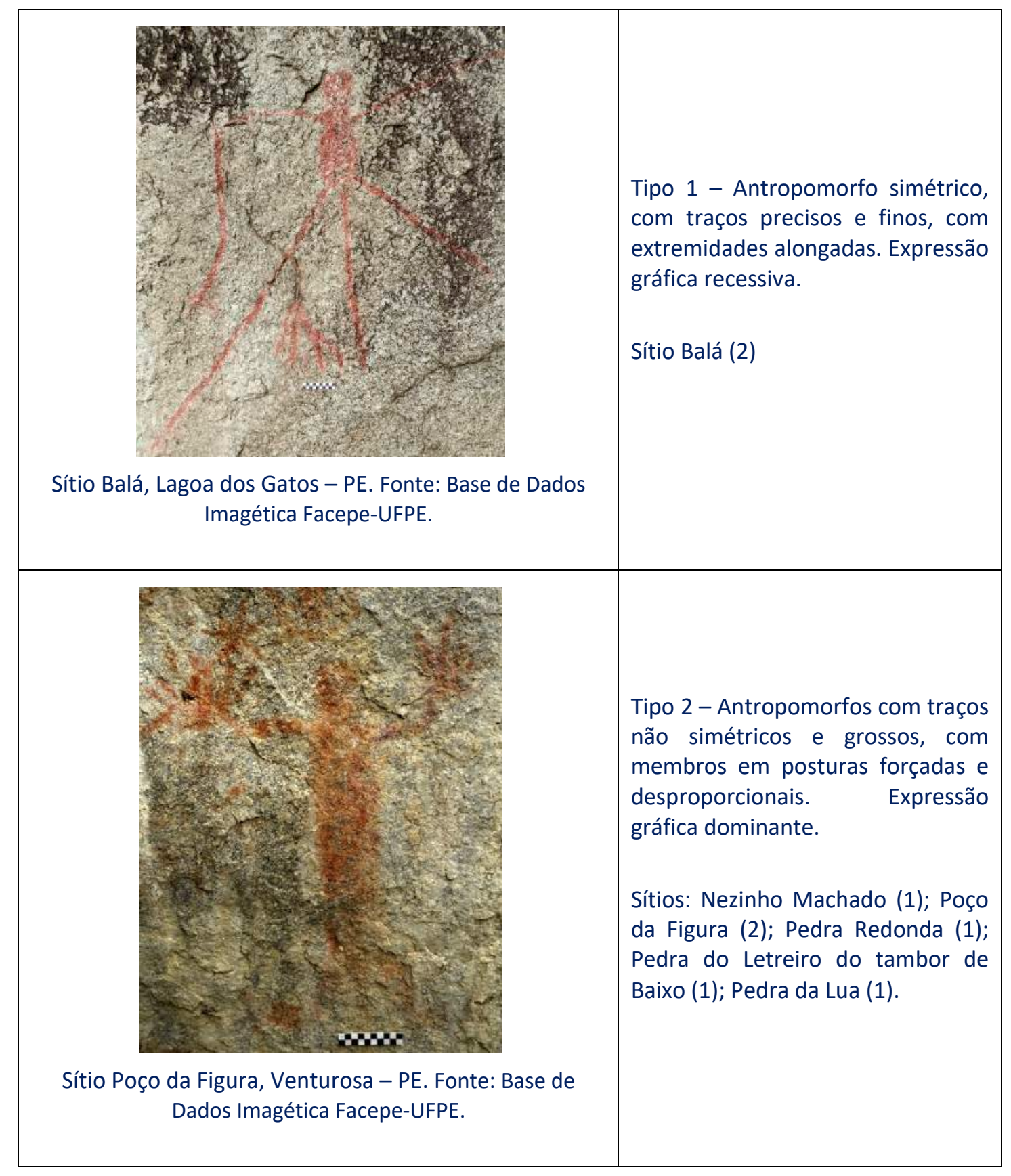




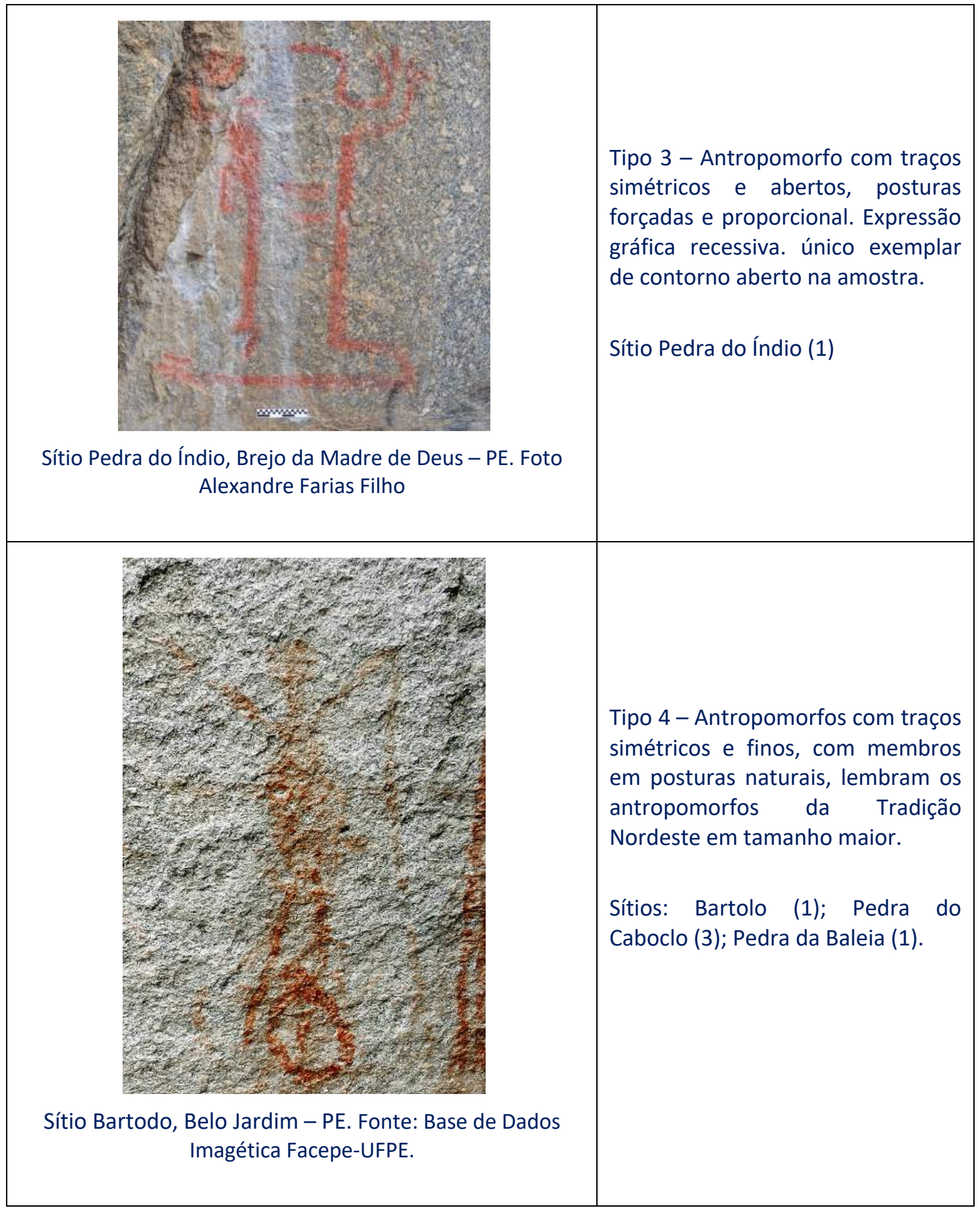

Os antropomorfos de grandes dimensões da Tradição Agreste foram descritos mais recentemente por Amaral (2014) como representações sem harmonia entre as partes que as compõem, desproporcionais e dotados de uma postura forçada. A falta de acuidade técnica, a assimetria e os traços irregulares nas representações das figuras antropomórficas são outras características destacadas pelos pesquisadores que se ocuparam em estudar a Tradição Agreste. 
De tal modo, essa pesquisa a partir da análise em relação as variáveis observou-se algumas recorrências:

Isolamento - Os antropomorfos de grandes dimensões são únicos nas manchas gráficas analisadas, com exceção de um conjunto no sítio Pedra do Caboclo. Apesar de serem de grandes dimensões, esses grafismos são graficamente bastante diversos da amostra estudada, pode-se dizer intrusivos para a área.

Cor - Observou-se que todos os grafismos levam o caracterizador monocromático. Apesar de apresentarem-se com certa constância o uso de bicromia em alguns grafismos da Tradição Agreste, para os antropomorfos de grandes dimensões a bicromia não foi constatada.

Morfologia e traço - Apresentou-se para a amostra estudada quatro tipos distintivos em relação a morfologia e o traço. Dentre os tipos analisados, pode ser destacado como representantes dos caracterizadores essenciais da Tradição Agreste o tipo 2. Os demais tipos, apesar do tamanho modal (igual ou superior a $51 \mathrm{~cm}$ ) não possuem os elementos destacados por Alice (1987), Martin (2013) e Amaral (2014) como característicos da Tradição Agreste. Apesar de ter o tamanho compatível ao tamanho modal expresso por Amaral (2014), esses possuem simetria, traços finos e com bastante acuidade, característicos de cenários da Tradição Nordeste.

A partir da análise dos elementos acima pode ser observado que a grande dimensão não é uma variável substancial para caracterizar os antropomorfos emblemáticos da Tradição Agreste. Contatou-se que antropomorfos de grandes dimensões, como os do tipo 1 e 4, possuem traços finos e bastante simétricos; o do tipo 3 tem técnica gráfica com marcadores bastante diferentes da Tradição Agreste, cujo caracterizador é o contorno aberto.

Assim, a variável tamanho, por si só, não é forte o suficiente para caracterizar os emblemáticos dessa Tradição, fazendo-se necessário a adição de outras variáveis como espessura do traço e morfologia, para dar aos antropomorfos de grande dimensão a particularidade de um emblemático da Tradiçao Agreste.

\section{Referências}

AGUIAR, A. A Tradição Agreste análise de 20 sítios de arte rupestres em Pernambuco. Dissertação de Mestrado apresentada ao Programa de Pós-Graduação em Historia - Área de Concentração em PréHistória da Universidade Federal de Pernambuco. Recife. 1986. 
AMARAL, M. P. V. As pinturas rupestres da Tradição Agreste em Pernambuco e na Paraíba - Brasil. Tese (Doutorado em Arqueologia). Universidade Federal de Pernambuco. Recife, 2014.

CALDERÓN, V. Nota Prévia sobre três fases da arte rupestre no Estado da Bahia. Universitas, Revista de Cultura da Universidade Federal da Bahia, $n^{\circ}$ 05, Salvador: UFBA, 1970.

CISNEIROS, D. Similaridades e Diferenças nas Pinturas Rupestres Pré-históricas de Contorno Aberto no Parque Nacional Serra da Capivara - PI. Tese (Doutorado em Arqueologia). Universidade Federal de Pernambuco. Recife, 2008.

DANTAS, J.de A. Indícios de uma Civilização Antiquíssima. João Pessoa: União Editora, 1994.

MARTIN, G. As pinturas rupestres do sítio Alcobaça, Buíque - PE, no contexto da Tradição Agreste. IN: CLIO Arqueológica № 18. Recife: EDUFPE, 2005.

MARTIN, G. Pré-História do Nordeste do Brasil. Recife: EDUFPE, 2013.

PESSIS, A-M; CISNEIROS, D.; MUTZENBERG, D.; MARTIN, G.; LAVALLE, H. Caracterização dos Sítios Préhistóricos com Grafismos Rupestres no Estado de Pernambuco, Brasil. Clio Arqueológica. Recife, v. 23, n. $1,2017$.

PESSIS, A-M. Identidades e Classificações dos registros gráficos pré-históricos do nordeste do Brasil. Clio Arqueológica. Recife, v.1, n.8, 1992.

PESSIS, A-M. Imagens da Pré-história. Parque Nacional da Serra da Capivara, Fumdham/Petrobras, 2013. PERAZZO, M.; PESSIS, A-M; CISNEIROS, D. As pinturas Rupestres da Tradiçao Agrestre em Pernambuco e na Paraiba. Fumdhamentos. São Raimundo Nonato. N. 12. 2015.

PORPINO, K. de O.; SANTOS JUNIOR, V. dos. SANTOS, M. de F. dos. Lajedo de Soledade, Apodi, RN Ocorrência peculiar de megafauna fóssil quaternária no Nordeste do Brasil TrabalhodivulgadonositedaSIGEP<http:// www.unb.br/ig/sigep>, em 31/7/2007. 